\title{
Arguing for Explanations: Logic and the Special Disciplines
}

\author{
Thomas Schwartz \\ University of Texas
}

\section{Introduction}

Informal logic studies forms and norms of argument-of inferential reasoning-concentrating on forms and norms common to diverse subject areas, aiming to develop practicable techniques for evaluating arguments and for constructing good ones.

The specimens of argument that have been examined by informal logicians are a peculiar lot: mostly they come from political speeches, "Letters to the Editor," advertising copy, and other pieces of pedestrian advocacy, with an occasional philosophical example thrown in. What is so peculiar about this is that we academics are surrounded by a bounty of profound, subtle, complex, and artful arguments. They are the arguments produced by scholars and scientists in their research. Such arguments share few of their salient features with the banal specimens that fill most books on informal logic. It is as though literary scholars had given most of their attention to comic books and pulp romances.

True, philosophers of science, mathematics, art, and other subjects have had something to say about the inferential reasoning employed in the special disciplines. But what they have said is quite abstract, lacking the richness, detail, and practical utility sought by informal logicians: their findings do not provide tools for constructing and assessing actual arguments.

Methodologists working within the several disciplines do provide such tools. But they have cast their nets narrowly, focusing on specific technical devices and on research paradigms, not treating the bulk of day-to-day reasoning within their disciplines.

Here I discuss a type of argument that I call analytical (using the term, as social scientists do, to mean "explanatory"). Although analytical reasoning pervades all academic subjects, it is most conspicuous in the social sciences. A piece of analytical reasoning begins with a fact or set of data and leads to an explanation thereof, or at least to a range of reasonable candidate explanations. It consists, among other things, in surveying and evaluating alternative explanations.

I do not explore all the ins and outs of analytical reasoning, though I hope to encourage further exploration by others. Instead I briefly sketch its structure and the norms governing it. Against this background I go on to answer four general questions about the relation of informal logic to the special disciplines:

- Does inferential reasoning within the special disciplines depend heavily upon generic forms and norms of argumentones that are in no way discipline specific?

- If so, are such forms and norms sufficiently rich, complex, and intellectually challenging that we may teach them separately and regard their use as a matter of skill?

- To what extent is mastery of the special disciplines a matter of reasoning skill as opposed to something that might be called substantive, factual, or discursive knowledge?

- To what extent are the reasoning skills required by the special disciplines specific to those disciplines rather than generic?

Although I have thought about these matters mostly from the point of view of my political-science experience, I hope to have said things which, after correction, refinement, and expansion by informal logicians with different disciplinary backgrounds, will be generally true. 


\section{ANALYTICAL REASONING}

Suppose you accept some fact as true but wonder why it is true. In thinking about this question-in seeking an explanation-you engage in analytical reasoning. If you go about it in a disciplined, systematic way, you will somehow survey a set of alternative explanations, investigate whether each alternative does explain the fact you want to explain in some minimum sense, and compare these alternatives, seeking if possible to rule some out as unacceptable or as inferior to others, and trying ideally to narrow the field to a unique "best" or "correct" explanation-though you may not have enough information to do the latter. Here is a homely example:

\section{Example 1}

Why are lgnatz's windows closed? He might have gone away for a while and closed them for protection against burglars. He might instead have closed them to keep his house warm. Another possibility is that he closed his windows to keep his house cool while running his air conditioner. Because Ignatz's lights and TV are on and his car is in the driveway with the garage door open, the first explanation is unlikely. And because it has been quite warm all day, the second is implausible. That leaves the third: Ignatz is probably running his air conditioner.

For philosphical and pedagogical purposes, it is useful to regiment analytical reasoning into the following four-step format:

Step 1. Specify an explanandum. This can be a single tact, a general observation, or a complex of data, depending on what you wish to explain.

Step 2. Formulate some alternative explanations, seeking quality and variety. In each case, list the important explanatory premise or premises. You need not list other steps (intermediate steps and less important premises) unless essential to clarity.

Step 3. For each explanation, show that the explanandum follows from the suggested explanatory premise(s) if it is not obvious that it follows. (Often it is obvious, and this step does not appear.)

Step 4. Evaluate the alternative explanations: Reject any explanation from which the explanandum does not follow. Reject any explanation that has a false, implausible, or question-begging premise. Compare the remaining explanations with respect to PLAUSIBILITY and ECONOMY. Seek grounds for eliminating some alternatives (as many as possible) or, at least, for concluding that they are less reasonable than some other alternatives.

A great many things remain to be said about this procedure. For now, four things must suffice:

Thing 1. Although an explanation listed at Step 2 could consist entirely of established truths, such as observation reports and laws of physics, most explanations involve at least one explanatory hypothesis-an explanatory premise provisionally assumed to see what it can explain.

Thing 2. It is not always possible to arrive conclusively at a single best explanation-let alone "the correct" one. Sometimes we do not have enough information to rule out any candidates. And even if we manage to select a best one, that choice may be tentative and weakly supported, hence open to revision in the face of new evidence. (This is why I do not describe the procedure as "arguing to the best explanation.")
Thing 3. The plausibility of an explanation-or, more accurately, of an explanatory premise-is the degree of confidence we may reasonably have in it, given known facts and accepted beliefs. In other words, the implausibility of an explanatory premise reflects the extent to which it conflicts with our reasonable convictions as well as the strengths of any convictions with which it conflicts.

Thing 4. Explanatory economy is a combination of two virtues: simplicity and explanatory power, simplicity being the opposite of complexity. Of two equally powerful explanatory premises, the simpler is the more economical. Of two equally simple premises, the more powerful is the more economical. One judges the economy of an hypothesis or other explanatory premise by estimating how powerful it is for its level of complexity. That is,

$$
E(\text { economy })=\frac{P \text { (explanatory power })}{C \text { (complexity) }}
$$

where

$$
C=\frac{1}{S \text { (simplicity) }}
$$

The explanatory power of a premise is measured (roughly) by the number and variety of the facts, actual and potential, that it explains. The complexity of a premise is measured (roughly) by its length, the number of words and clauses it contains, the degree of any polynomial expression occurring in it, and the like.

Compare explanatory economy with fuel economy. Of two cars, the one that burns less gasoline is not necessarily more economical, else a poorly tuned Cadillac limousine that was hardly used would be an economy car. Neither is the car that goes farther more economical, else an overloaded Land Rover with flat tires that was frequently driven across the Gobi Desert would be an economy car. A car's fuel economy is measured, not by how little gasoline it uses, nor by how far it goes, but by how far it goes on how little gasoline. Likewise, explanatory economy is measured, not by how much is explained, nor by how simple a set of premises. Economy of every sort is output per input-how much you get out for what you put in.

To illustrate, consider a town with two barber shops, Angelo's Unisex Coiffures in the north and Vito's Institute of Tonsorial Aesthetics in the south. Fifteen townsmen were asked the barber shop they used and the neighborhood in which they lived-northeast, southeast, southwest, or northwest. The results:

$\begin{array}{crr}\text { MAN } & \text { NEIGHBORHOOD } & \text { BARBERSHOP } \\ 1 & \text { NW } & \text { Angelo's } \\ 2 & \text { NE } & \text { Angleo's } \\ \text { Vito's } \\ 3 & \text { SW } & \text { Vito's } \\ 4 & \text { SW } & \text { Angelo's } \\ 5 & \text { NW } & \text { Vito's } \\ 6 & \text { SE } & \text { Vito's } \\ 7 & \text { SE } & \text { Angelo's } \\ 8 & \text { NE } & \text { Vito's } \\ 9 & \text { SE } & \text { Angelo's } \\ 10 & \text { NW } & \text { Angelo's } \\ 11 & \text { NE } & \text { Angelo's } \\ 12 & \text { NE } & \text { Angelo's } \\ 13 & \text { NW } & \text { Vito's } \\ 14 & \text { SE } & \text { Vito's } \\ 15 & \text { SW } & \end{array}$


How to explain these data? Five hypotheses:

(H) Northeasterners use Angelo's; southeasterners, Vito's; southwesterners, Vito's; and northwesterners, Angelo's.

$\left(\mathbf{H}_{2}\right) \quad$ Northerners use Angelo's, whereas southerners use Vito's.

$\left(\mathbf{H}_{3}\right)$ Townsmen use the barbershops closest to where they live.

$\left(\boldsymbol{H}_{4}\right)$ Townsmen tend to minimize distance from home when using services.

(H5) People tend to minimize distance from home when using services.

Each successive hypothesis is more economical than its predecessor. $\left(\mathrm{H}_{1}\right)-\left(\mathrm{H}_{3}\right)$ explain exactly the same behavior, so they are equal in explanatory power. But $\left(\mathrm{H}_{2}\right)$ is simpler than $\left(H_{1}\right)$, and $\left(\mathrm{H}_{3}\right)$ is simpler still. $\left(\mathrm{H}_{4}\right)$ is about as simple as $\left(\mathrm{H}_{3}\right)$, but it has much greater explanatory power since it explains many actions besides going to the barbershop. $\left(\mathrm{H}_{5}\right)$ is at least as simple as $\left(\mathrm{H}_{4}\right)$, and it has greater explanatory power because it applies to all people, not just male denizens of the town in question.

Because they are more powerful, $\left(\mathrm{H}_{4}\right)$ and $\left(\mathrm{H}_{5}\right)$ are somewhat less plausible than $\left(\mathrm{H}_{1}\right)-\left(\mathrm{H}_{3}\right)$. But not significantly less: it is hard to believe that the goal of minimizing distance is peculiar to barbershop users in the town in question. All things considered, then, $\left(\mathrm{H}_{5}\right)$ seems to be the best explanation of the lot.

Later hypotheses in the list of $\left(\mathrm{H}_{1}\right)-\left(\mathrm{H}_{5}\right)$ are better than earlier ones because more economical. Still, earlier ones are not incorrect on that account. They are just less than the best. The reason is evident enough: The later hypotheses explain the ealier ones. So if a later one is true, any ealier one probably is true as well, and a true hypothesis can hardly be call. ed incorrect.

Notice how the hypotheses that attribute underlying mechanisms, processes, or motivations to the occurrences they explain are more economical than those that do not. That tends in general to be the case, since what we regard as underlying explanatory factors (as opposed to more superficial ones) give unity to apparently diverse phenomena, thereby both simplifying and extending our account of the worldmaking this account both simple and powerful, that is.

Notice also that the more general hypotheses are more economical than the less general ones. That, too, tends in general to be the case. For the more general of two (universal) sentences normally has about the same structure as the less general one, making it about as simple; but it covers a more inclusive class of cases, which means it is more powerful. Lesson: A good way to generate more economical alternatives to a given premise is by generalizing it, by expanding a category (townsmen to people), by replacing some word or phrase ("townsmen") with a more general word or phrase ("people"). A closely related way is by fusing categories, by replacing two or more words ("northeasterner," "northwesterner") with one ("northerner") in which their meanings combine. That way preserves power while increasing simplicity.

Notice finally that the better hypotheses in the list seem more genuinely explanatory than the less good ones. Intuitively, there is a sense in which $\left(\mathrm{H}_{1}\right)$ and $\left(\mathrm{H}_{2}\right)$ are mere generalizations whereas $\left(\mathrm{H}_{3}\right)-\left(\mathrm{H}_{5}\right)$ are explanations in the strongest sense. Following common usage in the social sciences, I prefer to cast my explanatory net widely and count the likes of $\left(\mathrm{H}_{1}\right)$ and $\left(\mathrm{H}_{2}\right)$ as explanations-rather as one might cast one's aesthetic net widely and count schoolboy drawings as art. Our feeling that only $\left(\mathrm{H}_{3}\right)-\left(\mathrm{H}_{5}\right)$ are explanatory in the strongest sense might still be explained by their relatively high level of economy.

Here are three examples of analytical reasoning in the four-step format:

Example 2.

Fact:

After the Civil War, the Radical Republicans, who controlled Congress, instituted Military Reconstruction of the South, disenfranchising white Southerners.

Alternative explanations:

(a) The Radical Republicans wanted to punish white Southerners for rebelling and to protect newly freed Negroes.

(b) The Radical Republicans wanted to increase their share of the vote, especially in a way that would seem justified on nobler grounds. Because white Southerners were Democrats and Negroes Republicans, disenfranchising the former and protecting the latter increased the Republican share of the vote.

(c) Political parties tend to try to increase their share of the vote, especially in ways that seem justified on nobler grounds.

Comparative evaluation: Barring further information, (a) and (b) are about equally plausible. (c) is about as plausible as (b), and, being more general, it is more economical.

\section{Example 3.}

Fact:

Virtually all states have adopted the winner-take-all rule for presidential elections: the candidate with the greatest number of popular votes wins all of a state's electoral votes.

Alternative explanations:

(a) States think this rule is fair.

(b) States think this rule will help discourage minor-party candidates, as they wish to do.

(c) Each state wants the reward for winning and the penalty for losing the state to be as great as possible to encourage presidential candidates to offer the state as much as possible.

Comparative evaluation: (b) is more plausible than (a) because the value judgment it attributes to the states is more reasonable. (c) is more plausible still because the motive it attributes to the states is more self-serving.

\section{Example 4.}

Fact:

Since food stamps were introduced, recipients have increased their spending on liquor.

Alternative explanations:

(a) Food-stamp recipients have been illicitly selling some of their food stamps, thereby increasing the money they have to spend on liquor.

(b) Since food stamps were introduced recipients have had to spend less of their incomes on food, leaving more for liquor.

(c) As the price of a good to a consumer decreases (owing, perhaps, to a government subsidy), he spends less of his budget on that good, leaving more for other goods. 
Comparative evaluation: (b) is more plausible than (a). (c) is no less plausible than (b) but much more general. Therefore, (c) is best.

\section{GENERIC FORMS AND NORMS OF ARGUMENT}

Does reasoning within the special disciplines depend heavily on generic forms and norms of argument-ones that are not discipline specific?

Analytical reasoning is found in every branch of science and scholarship. This is obvious in the case of the natural and social sciences. To the extent that a science has evolved a single, generally accepted explanatory theory, deductive reasoning becomes more prominent that analytical reasoning, which emphasizes the construction and comparative evaluation of alternative explanations. Thus, explicit analytical

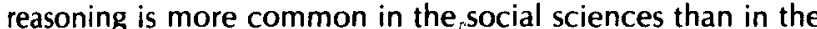
natural sciences, and more common in political science and sociology than in linguistics or economics. But every science has some room for analytical reasoning.

Fictional detective heroes engage quite explicitly in analytical reasoning, attempting to explain apparent crimes by formulating and critically evaluating alternative explanatory hypotheses, each attributing crime, method, and motive to scme character. I suppose real detectives use analytical reasoning as well. Certainly historians do. Those I have in mind are not just analytical or social-scientific historians, but traditional historical scholars, who attempt to construct plausible, economical stories that best explain incomplete and possibly spurious records of part episodes. The interpretations offered by art and literary critics, too, are explanatory hypotheses, chosen and defended as best explanations of various features of the work in question. Even philosophers use analytical reasoning, at least implicitly, when they concoct normative principles and definitions and test them against imaginary examples: in effect, they seek best explanations of their intuitive judgments about these examples. If philosophers often are not as explicit as scientists, historians, and literary critics in ruling out alternative explanations of their data, that is a shortcoming of philosophy.

Often analytical reasoning occurs only implicitly, or in formats very different from the canonical one I have discussed. A scholar or scientist who investigates the authenticity or reliability of data of any sort is, in effect, surveying and evaluating alternatives to the hypothesis that the world is as it appears to be. Or consider enumerative induction: an hypothesis attributing some feature to a population is inferred from the fact that a given sample of the population exhibits that feature. For the reasoning to be any good, the sample must be shown to be fair, or unbiased (unless this is obvious). But to call a sample fair or unbiased is just to say that it has been constructed so as to rule out alternative explanatory hypotheses. Suppose I say, "My, what yummy-looking strawberries i I think I'll take a basket." Because all one can see of a basket of strawberries is the top layer, I have implicitly generalized yummy appearance from a sample comprising the top layer to a population comprising all the strawberries. The reasoning is poor, of course, because the sample is biased or unfair. Here is another way to put this criticism: I failed to rule out the alternative hypothesis that the best strawberries were selected and placed on top to attract customers-quite a plausible hypothesis at that. Like fair samples, experimental controls are implicit devices for ruling out alternative explanations. Many statistical methods, such as regression analysis, have the same end.
By making explicit inferential moves that would otherwise not be explicit, the four-step and analytical-reasoning format can aid understanding and help prevent error. This is true in everyday life as well as the academic disciplines. For analytical reasoning is essential to the problem-solving abilities of nonacademics, who must continually concoct defensible explanations in order to understand and thereby control their environment.

\section{GENERIC REASONING SKIU}

Are generic forms and norms of argument-ones not specific to any discipline-sufficiently rich, complex, and intellectually challenging that we may teach them separately and regard their use as a matter of skill (as opposed to mere competence)? In particular, is there such a thing as skill at analytical reasoning generally, as opposed to its disciplinespecific versions?

There is, I think, for two reasons:

First, even without becoming clever at concocting explanatory hypotheses, contriving tests for comparing them, and the like, one can through practice become increasingly comfortable and facile with the four-step format and increasingly sensitive to analytical reasoning when one encounters it.

Second, there is a rich set of discipline-independent heuristics whose mastery, which requires practice, obviously would improve the quality of one's analytical reasoning. Here is a set of heuristics that I devised for generating alternative explanations of a given fact, especially in the social sciences:

- Brainstorm: rapidly and roughly jot down any explanations that come to mind, not worrying about how reasonable or how well written they are; then go back and clean them up-but not until you have run out of explanatory gas.

- Draw upon familiar (standard, traditional) explanations and ones used to explain related phenomena.

- Of each explanation already listed, ask: If this were not true, what else-what other hypothesis, however bizarre-would explain the fact at issue?

- Try to vary or modify explanations already listed.

- Try to generalize explanations already listed: expand categories.

- Try to simplify explanations already listed by fusing categories: instead of saying one thing about two categories separately, say it about a single, combined category.

- Look for patterns or uniformities among the data presented at Step 1.

- Look for underlying processes, mechanisms, or motivations.

- When explaining behavior, look at actors' preferences and goals, expecially announced preferences and goals, selfish ones, and ones that are common to actors of their illk.

- Put yourself in the actors' shoes. Ask: If I were they, why would I do this?

- Break down the fact being explained into its component elements-the objects, people, events, features, ideas, and relationships referred to in the fact. Then ask of each component how it or elements of its kind typically function or behave. In particular, break down group actions into individual actions.

The following are two examples of analytical reasoning us ing these heuristics: 


\section{Example 5.}

Fact:

The turnover of membership in the Texas House of Representatives is more rapid than in the U.S. House of Representatives.

A key component of this fact is the process of turnover, which can itself be broken down into individual acts of leaving office. Why would a legislator leave office? One reason is that he has lost an election. Another is that he has chosen not to run again. This suggests two alternative explanations:

(a) American voters are more pleased with their congressmen than Texas voters are with their state representatives.

(b) U.S. representatives find their jobs more attractive than Texas state representatives do.

And (b) can be generalized as follows:

(c) Higher-ranking officials find their jobs more attractive than lower-ranking officials do.

Brainstorming might have begot:

(d) U.S. representatives have longer terms of office than Texas state representatives.

Because two components of the explanandum are the U.S. and Texas Houses of Representatives, we might look for salient differences between these bodies. Here are two such:

(e) The Texas House of Representatives is a branch of state government, whereas the U.S. House of Representatives is a branch of federal government.

(f) The Texas House of Representatives is smaller than the U.S. House.

Comparative evaluation: Because it is almost certainly true, (b) is more plausible than (a). (c) is about as plausible as (b), and it is more economical because more general. (d) is false: both U.S. and Texas representatives serve two-year terms. The explanatory conclusion does not follow from (e) or (f). Thus, (c) is the best.

Example 6.

Fact:

The percentage of women in the U.S. work force has increased enormously in the past decade.

This refers to women and to the past decade, suggesting that Women's Lib may be involved in the explanation:

(a) The Women's Liberation movement has opened more job opportunities for women in the past decade.

(b) The Women's Liberation movement has encouraged women to expand their job horizons in the past decade.

The explanandum also refers to new employment. Why would anyone obtain new employment? One reason is that new employment opportunities exist, an idea already used in (a). Another is that the need or desire to work has increased, suggesting:

(c) Owing to inflation, women have increasingly had to enter the work force to help support their families during the past decade.

And this can be generalized:

(d) Women tend to enter the work force at a higher rate when family real incomes drop.

We might instead have found (c)-(e) by examining actors' preferences or by breaking the fact to be explained down into individual acts by women of seeking new employment.

Comparative evaluation: (a)-(e) are all quite plausible. (c) is slightly more plausible than (a) or (b) because it does not attribute casual efficacy to a specific social movement or interest group. (d) and (e), especially (e), are nearly as plausible and more general, hence more economical, than (c).
Although some of the heuristics in my list are more appropriate to the social than the natural sciences, they are no more discipline-specific than that, and most are not even that specific. Thus, there is a great deal to teach and to learn about analytical resoning that is not part of mastering any special discipline but that can improve one's mastery of many disciplines.-

\section{DISCIPUNARY MASTERY AND REASONING SKILL}

To what extent is mastery of the special disciplines a matter of reasoning skill as opposed to something that might be called substantive, factual, or discursive knowledge?

Certainly to be a good political scientist, biologist, clasicist, or whatnot is not just to be able to parrot the established acts, received wisdom, and prominent doctrines of that discipline. It involves the ability to explain the facts, to defend the wisdom, to evaluate the doctrines, and to do so rigorously and artfully. It involves, therefore, a great deal of reasoning skill.

Besides reasoning skill, what does disciplinary mastery consist of? Two obvious candidates are factual knowledge and understanding. Let us examine each in turn, asking what it is and whether and how it combines with reasoning skill to produce disciplinary mastery.

Factual knowledge is itself an ability, even if not a skill. It is the ability to retrieve facts on cue. Such knowlege varies not only in the facts retrieved but in the cues that occasion the retrieval. In particular, what we regard as mere discursive knowledge of facts is the ability to retrieve those facts in the face of traditional schoolboy cues- "Who was so-and-so?" "When did thus-and-thus happen?" "What is such-and-such?"

Factual knowledge-the ability to retrieve facts on cue-also is part of reasoning skill within the special disciplines. But there it differs from mere discursive knowledge of facts in that the cues on which it is based are more complex and subtle than the traditional schoolboy cues. Suppose I want to explain the following fact:

$\left(\mathbf{F}_{2}\right)$ Voter turnout in congressional general elections is lower in southern states than in other states.

In listing alternative explanations of $\left(F_{1}\right)$, one candidate I would include consists of those two statements:

(H) People develop the habit of voting in general elections to a greater degree when there is partisan competition than when there is none.

(F2) Until recently, the southern states were one-party states, with a single candidate in any general election for Congress.

Here I have explained one fact $\left(F_{1}\right)$, by citing an hypothesis, $(H)$, plus another fact, $\left(F_{2}\right) . I$ retrieved the latter fact in the face of a cue, viz., the problem of explaining $\left(F_{1}\right)$. But the ability to retrieve $\left(F_{2}\right)$ in the face of such cues is of a higher intellectual order than the ability to retrieve the same fact in the face of traditional schoolboy cues. It is sufficiently higher, I believe, to warrant the term skill. It is not a case of rote memory-of mere discursive knowledge. I could not have acquired this ability merely by impressing a pair of correlated expressions (such as "Battle of Hastings" and "1066") on my memory. In retrieving the relevant information, I had a larger, more diverse, less clearly demarcated set of items to search. 
Insofar as mastery of a discipline requires factual or substantive knowledge, such knowledge is not neatly separable from reasoning skill within that discipline. Factual knowledge that is tied to the most intellectually important cues is, indeed, an integral part of disciplinary reasoning skill.

Much the same is true of understanding within a discipline. What constitutes understanding of a subject if not the ability to concoct and defend good explanations of the facts of that subject and to use those facts to explain other facts? It seems to me that professors who do not teach reasoning skills to any significant extent but who aver that they give students an "understanding" of their subject really mean that they try to foist their own favorite explanations on students without trying to help students get good at adducing and critically evaluating alternative explanations. Expert opinion aids understanding, to be sure, but it does so as a source of alternative explantions, not as something to recite by heart. "Understanding" without analytical-reasoning skill is a shadow of genuine understanding.

It is true, in a sense, that mastery of a discipline requires factual knowledge and understanding as well as reasoning skills. But in the sense in which this is true, factual knowledge and understanding are not separate from reasoning skills. They are themselves reasoning skills.

\section{DISCIPLINE-SPECIFIC REASONING SKILLS}

To what extent are the reasoning skills required by the special disciplines specific to those disciplines rather than generic?

Although analytical reasoning crosses disciplines, the skills it requires in each discipline are, in part, specific to that discipline in four ways:

Way 1. As the voter-turnout example illustrates, factual knowledge specific to a given discipline often is used to concoct good explanations within that discipline. But to do so, one cannot combine generic analytical-reasoning skills with mere discursive knowledge of facts. For such knowledge is tied to a set of cues insufficient for anlytical reasoning. One must be able to retrieve the relevant facts, not just in the face of traditional schoolboy cues, but in the face of explanatory problems. And this is an additional skill, requiring practice within the special disciplines, even for those who have acquired generic analytical-reasoning skills.

Way 2. The ability to concoct, apply, test, and compare good explanations within a discipline depends on a familiarity with any number of discipline-specific concepts-momentum, convex technology, documentary authenticity, socialization, meiosis, separation of powers, and whatnot. And clearly it is not enough to possess generic analytical-reasoning skills plus the ability to recite memorized definitions of these concepts. You can memorize a definition of socialization without being good at recognizing cases of it. You can memorize a definition of momentum without seeing how to use this concept to explain why inferior bicycles tend, somewhat paradoxically, to coast farther than superior ones in Consumers' Union tests.

Way 3. In a similar way, analytical-reasoning skills within a discipline include familiarity with discipline-specific theories, models, and paradigms. As anyone who has studied physics or economics knows, mere discursive knowledge of a theory is not enough; one must practice applying it to be able to apply it correctly and to appreciate opportunities to apply it.

Way 4. Besides generic analytical-reasoning heuristics, there are discipline-specific and, indeed, subject-specific heuristics for analytical reasoning. To cite a small example, one's ability to explain features of the U.S. Constitution and actions taken by the Constitutional Convention of 1887 can be enhanced by looking always for compromises between the pairs of interests on the following checklist: Large states versus small, slave versus free, south versus north, trade and manufacturing versus agriculture, unfettered commerce versus states' rights, fear of monarchs versus fear of majorities.

\section{CONCLUSION}

Mastery of most special disciplines requires generic analytical-reasoning skills, which might be studied and taught under the rubric of informal logic. Such mastery cannot be reduced, however, to generic analytical-reasoning skills plus mere discursive knowledge of discipline-specific facts, concepts, and theories. The discipline-specific ingredients are themselves reasoning skills, or aspects of such, best taught by the special disciplines themselves. Put another way, disciplinary mastery does consist of generic reasoning skill plus a certain knowledge of discipline-specific facts, concepts, and theories, but this knowledge is not merely discursive: the cues on which it is based are reasoning tasks, not oldfashioned schoolboy questions.

Besides having neglected the rich examples of argument to be found in the various departments of science and scholarship, informal logic has neglected constructive techniques, concentrating on the criticism of bad arguments much more than the construction of good ones. By taking up analytical reasoning in the way I have suggested, we can remedy both deficiencies: although related to a critical technique that I have discussed at length elsewhere, 2 the four-step procedure discussed here is constructive rather than critical.

Because disciplinary mastery requires generic reasoning skills, there are mutual gains to be realized from commerce between informal logic and the special disciplines. We informal logicians fail to exploit a rich source of data and ideas while painting a badly biased picture of argument if we ignore the arguments found in the special disciplines. We also lose an opportunity to play a more visible, more central, more widely appreciated role in academic life.

\section{NOTES}

* A slighty revised version of a paper presented to the Second International Symposium on Informal Logic, University of Windsor, June 1983. I thank the University of Texas for support of a project on which this paper is based, my colleagues Charles Cnudde, Terry Sullivan, and Harrison Wagner for helpful discussions of my topic over the years, and Tony Blair for his initial help with the form and direction of this paper.

1 My argument here seems to refute that of John McPeck, who, in Critial Thinking and Education (Oxford: Martin Robertson, 1981), argues that there is no general skill that can be called critical thinking: students cannot be taught to think critically in general but only to think critically about particular subjects. 1 am not sure whether and to what extent McPeck and I really disagree, however, because his notion of "critical thinking" is quite different from my notions of "informal logic" and "generic reasoning" (whereof see esp. p. 13 of McPeck's book).

2 I mean criticizing a given explanation of a fact by citing a reasonable alternative explanation of the same fact, a task 1 discuss at length in Chapter 10 of my The Art of Logical Reasoning (New York: Random House, 1981).

Thomas Schwartz, Department of Government, University of Texas, Austin, Texas, $\mathbf{7 8 7 1 2 .}$ 